\title{
Alliance Capabilities and External Opportunity-Recognizing Integrative Capabilities: Creating Competitive Advantage in eLearning Innovation
}

\author{
Peiwen Liao \\ Department of Human Resource Management and Development, HSIUPING University of \\ Science \& Technology, Taiwan \\ Email: pearlliao@hust.edu.tw
}

Received 26 April 2016; accepted 17 May 2016; published 20 May 2016

Copyright (C) 2016 by author and Scientific Research Publishing Inc.

This work is licensed under the Creative Commons Attribution International License (CC BY). http://creativecommons.org/licenses/by/4.0/

cC) (7) 0pen Access

\begin{abstract}
This research develops an external opportunity-recognizing integrative capabilities perspective to explain how firms create competitive advantage in eLearning innovation using structural equation modeling analysis. The results revealed that both alliance capabilities and external opportunityrecognizing integrative capabilities had significant positive impact on eLearning innovation. Additionally, the results showed that external opportunity-recognizing integrative capabilities had a stronger impact on eLearning innovation than learning capacities. The core contribution of this paper is to provide insights into the external resource renewal processes; it delivers a deeper understanding of how firms employ external opportunity-recognizing integrative capabilities to develop new resource positions and how they create competitive advantage in eLearning innovation on the basis of external resources.
\end{abstract}

\section{Keywords}

External Opportunity-Recognizing Integrative Capabilities, Competitive Advantage, eLearning Innovation

\section{Introduction}

The 21st century is the era of knowledge economy, innovation will be as the basis for progress in organization's sustainable development, and the market competition also has become fiercer [1]. eLearning innovation, or 
innovation practice and performance are the major dependent variables in our study. ELearning systems should therefore be studied as mainstream information systems, within the paradigms of information systems evaluation research or organization innovation performance results. Innovation in eLearning-based companies is derived from their dynamic capabilities to create, deploy, and configure resources and renew, reconfigure, and redeploy the firm's resource base in response to environmental changes and uncertainties. Teece, Pisano, and Shuen [2] proposed that a firm must possess dynamic capabilities to constantly reconfigure, renew, and redeploy its resources and capabilities to capture and exploit changing opportunities [3]. International scholars have a strong tradition of studying inter-organizational relationships, in which alliance capabilities are a fundamental derivative of organizational learning [4] [5], partner selection [6] [7].

Our study's independent variables are resource stock and external opportunity-recognizing integrative capabilities. While the former focuses on technical fitness, which is doing what a resource or capability is supposed to do, the latter emphasizes evolutionary fitness, which is making a sustainable living in adaptation to the environment [2].

In our study, we distinguish between two constructs, resource stock of alliance capabilities and external opportunity-recognizing integrative capabilities, and then explore the relationship between these two constructs and their impact on firm innovation. We conjecture that (1) Both firm resource stock of alliance capabilities and external opportunity-recognizing integrative capabilities affect eLearning innovation; (2) The firm resource stock of alliance capabilities has an impact on its integrative capability; and (3) The effect of firm resource stock of alliance capabilities on innovation are all mediated by a firm's external opportunity-recognizing integrative capabilities.

\section{Literature Review}

\subsection{Alliance Capabilities and Innovation}

Zhou, Du and Han [8] found that the selection of alliance partners directly affects the operation and management of technological standard alliances. Appropriate partners among technological standard alliance played a significant role in improving partners' independent innovation capability. The empirical results showed that potential cooperative partners' reputation, compatibility and standardization ability had an obvious effect on innovation performance.

Prior work views alliance capabilities as a means to increase efficiency reduce costs, or foster innovation by gaining access to cutting edge technologies, specialized resources, and learning opportunities and innovation performance implications [8]-[12]. Therefore, we formulated the following hypothesis:H1:Alliance capabilities will have a positive effect on eLearning innovation.

\subsection{External Opportunity-Recognizing Integrative Capabilities and Innovation}

By carrying out their deployments on an enterprise-level basis, many organizations are able to leverage their powerful functionalities and eLearning-like integrative capabilities to put together knowledge and ability systems. Such integrative capabilities should foster the organization's awareness of innovation potentials and enhance their likelihood. Cohen and Levinthal [13] argue that the ability of a firm to recognize the value of new external information, to assimilate it and apply it to commercial ends is critical to innovation.

Liao, Kickul, and Ma [14] use external opportunity-recognizing integrative capabilities to represent a construct that refers to active listening. Information and knowledge can be obtained from a wide variety of sources. The generation of external information should an organization-wide activity. Additionally, firms need to scan frequently and broadly. The more information the organization gathers through the search process, the more options are there for identifying changes in the competitive and market environment, and therefore, the better chance a firm has to engage in innovation, both content wise and process wise. In according to the external demands, creating innovative performance offerings while learning and acquiring new knowledge and capabilities. Thus, we argue, H2: External opportunity-recognizing integrative capabilities will have a positive effect on eLearning innovation.

\subsection{Alliance Capabilities and External Opportunity-Recognizing Integrative Capabilities}

Thus alliance capabilities formation involves complexity due to environmental uncertainty, and requires significant 
organizational learning, but there are other means by which firms learn. An alternative approach to dealing with uncertainties related to the outcomes of strategic actions is by mimicking competitor actions. It is largely a function of an organization's prior related knowledge and capabilities within an organization that makes an organization more sensitive to certain information, knowledge, and integrative capabilities [14] [15]. The firm's integrative capability has to be utilized in the context of mobilizing existing alliance capabilities of the firm in sensing and even shaping opportunities and threats [2]. The ability to recognize opportunities depends in part on the alliance capabilities and knowledge in areas. The greater an organization's alliance capabilities the greater that organization's absorptive capability, the more capable an organization is of recognizing integrative capabilities. We hypothesize the following: H3: Alliance capabilities will have a positive effect on external opportunity- recognizing integrative capabilities.

\subsection{Alliance Capabilities, External Opportunity-Recognizing Integrative Capabilities, and eLearning Innovation}

The external opportunity-recognizing integrative capabilities lead to innovation primarily through the provision of a direction and opportunity in which to deploy and utilize alliance capabilities. In a similar vein, integrative capabilities help an organization to be aware of an opportunity's viability, and to mobilize the necessary resources and capabilities for the execution. The external opportunity capitalizing integrative capabilities ensures adjustment to and alignment with the environment in a timely fashion, and likely innovation in process learning and eventual product and service offering, innovation needed to create and capture customer value [14]. As such, external opportunity-recognizing integrative capabilities mediate the effects of its alliance capabilities on eLearning innovation. Therefore, we contend, H4: External Opportunity-Recognizing Integrative Capabilities mediate the positive effect of alliance capabilities on eLearning innovation.

\section{Methodology}

This study uses a quantitative survey to test inferred hypotheses empirically. In this part, we discuss the sample, data collection and measurements of research variables.

\subsection{Samples and Data Collection}

The data cited the Institute for Information Industry in 2012 for Taiwan's industry education and training for key industries and digital learning. Respondents are from the Taiwan region (not including the outlying islands and offshore islands region). Investigation population was already published in the magazine on 2012, which investigation include 1000 for the manufacturing industries, 500 for the services industries, 100 for the financial industries and total of 249 valid questionnaires.

To ensure the scale's validity, the items selected must represent the concept about which generalizations are to be made. Therefore, the items measure resource stock, external opportunity-recognizing integrative capabilities, eLearning Innovation. The measures were evaluated by experts from the eLearning field. Accordingly, the items were adjusted to make their wording as precise as possible. Likert scales $(1-7)$, with anchors ranging from strongly disagree to strongly agree, were used for all construct items.

\subsection{Measurement}

To assess the resource stock of an entrepreneurial firm with regard to its functional capabilities, we used previous studies of measurement survey of Hartman, Sifonis, and Kador's [16], and Liao, Kickul, and Ma [17] "We have strong relationships with our extended eLearning in our enterprise," and "We have a strong set of partnership with complementary eLearning players."

To measure external integrative capabilities, we adapted four items from Hills, Lumpkin, and Singh [18] scale on opportunity identification/recognition. Entrepreneurs were asked to indicate the extent to which ideas for new products/services come from external sources, including "Observing customer's needs/problems because eLearning implementation," and "Observing product/service/process problems because eLearning implementation.” Cronbach's alpha of this scale was 0.90 .

For eLearning innovation, we used three items from Hartman, Sifonis, and Kador's [16] Internet Readiness 
Measure: "We are continually introducing new eLearning offer our employee”; "We have a strong, rapid development platform for eLearning applications"; "We have a strong, rapid development material for eLearning applications," and "We continually innovation our eLearning functions offerings through iterative projects adding to their functionality." Cronbach’s alpha of this scale was 0.87 .

\subsection{Statistical Analysis}

Responses from participants were encoded and analyzed by the help of SPSS 19 and LISREL 8.8 for easier information interpretation. Structural equation modeling (SEM) includes confirmatory factor analysis, path analysis, and partial least squares path analysis. We were using LISREL 8.8 to assess unobservable latent construct, about alliance capabilities, and external opportunity-recognizing integrative capabilities, and eLearning innovation.

\section{Data Analysis}

\subsection{Measure of Constructs Reliability and Validity}

In this research, SPSS was initially used and final validation was conducted using LISREL 8.8. We followed each step to measure the reliability and validity of our model. The correlation matrix was computed for each item using items belonging only to the same construct. In Table 1 , all items were between 0.451 and 0.867 . The minimum acceptable value to keep a scale item with the latent construct is .5. More stringent reliability coefficients of 0.70 or higher have been recommended [19]. Cronbach's alphas were computed for each construct. The result of the CFA analysis was the identification of three constructs' resource stock of alliance capabilities (AC), external opportunity-recognizing integrative capabilities (EOR) and ELearning Innovation (eIN).

A CFA using SEM was performed on the final measurement model. All scale items were loaded on their indicated latent construct and higher than the more stringent standard of 0.80 . The goodness of fit indices reviewed earlier was used to assess the validity of the measurement model. The NFI, NNFI, CFI, and IFI all exceeded the 0.95 criteria for the model to be considered a close fit. The RMSEA was in the range of a near fit for the model. The results of the assessment of the reliability and validity of measures are reported in Table 2.

\subsection{Structural Equation Modeling}

The structural model testing the research model and hypotheses met the more stringent standard of 0.95 for the NFI, NNFI, and CFI fit indices to indicate a model of close fit. The RMSEA resulted in a value of 0.07, which indicated a model of fit. Four fit indices meet the standard for close fit, making the model an adequate test for the hypotheses. The total results are shown in Table 3.

The standardized path coefficients and the hypotheses status are represented in Figure 1. All hypotheses presented in the research model, H1 through H3 achieved a significance level of 0.01 .

Table 1. The correlation matrix.

\begin{tabular}{|c|c|c|c|c|c|c|c|c|c|}
\hline Sub construct & AC1 & AC 2 & EOR 1 & EOR 2 & eIN1 & eIN2 & eIN3 & eIN4 & Cronbach's alphas \\
\hline \multicolumn{10}{|l|}{ AC 1} \\
\hline & & & & & & & & & \multirow[t]{2}{*}{0.815} \\
\hline AC 2 & $0.687^{*}$ & & & & & & & & \\
\hline EOR1 & $0.472^{*}$ & $0.530^{*}$ & & & & & & & \multirow[b]{2}{*}{0.860} \\
\hline EOR2 & $0.470^{*}$ & $0.510^{*}$ & $0.755^{*}$ & & & & & & \\
\hline eIN1 & $0.515^{*}$ & $0.463^{*}$ & $0.458^{*}$ & $0.536^{*}$ & & & & & \multirow{4}{*}{0.947} \\
\hline eIN2 & $0.535^{*}$ & $0.523^{*}$ & $0.484^{*}$ & $0.549^{*}$ & $0.839^{*}$ & & & & \\
\hline eIN3 & $0.488^{*}$ & $0.513^{*}$ & $0.531^{*}$ & $0.587^{*}$ & $0.807^{*}$ & \multicolumn{2}{|l|}{$0.867^{*}$} & & \\
\hline eIN4 & $0.451^{*}$ & $0.459^{*}$ & $0.505^{*}$ & $0.586^{*}$ & $0.778^{*}$ & $0.813^{*}$ & $0.808^{*}$ & & \\
\hline
\end{tabular}

*Significant at $P<0.001$. ( $\mathrm{N}=249)$. 


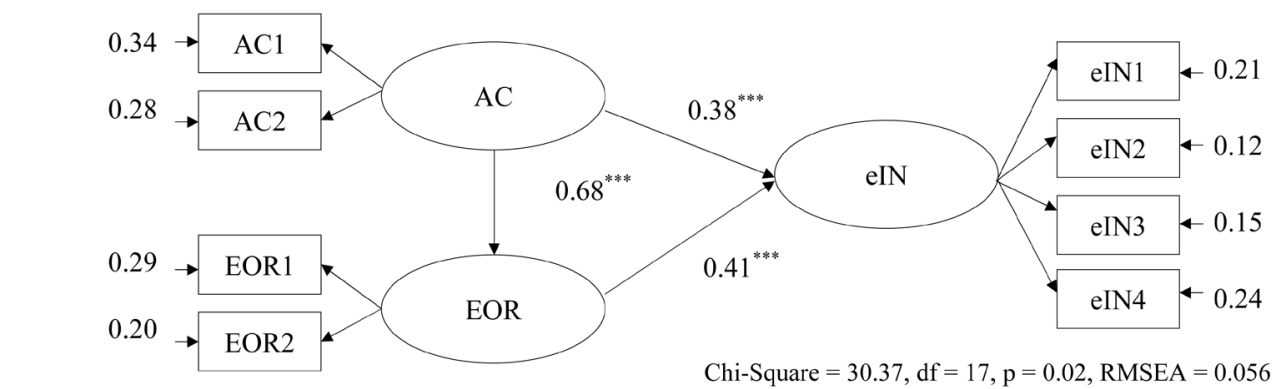

$\mathrm{NFI}=0.989, \mathrm{NNFI}=0.992, \mathrm{CFI}=0.995, \mathrm{IFI}=0.995$

Chi-Square $=30.37, \mathrm{df}=17, \mathrm{p}=0.02, \mathrm{RMSEA}=0.056$

Figure 1. Research model.

Table 2. Results of confirmatory factor analysis of independent and dependent variables.

\begin{tabular}{|c|c|c|c|c|}
\hline Construct & Item & $\lambda$ & CR & AVE \\
\hline $\begin{array}{c}\text { Alliance } \\
\text { Capability (AC) }\end{array}$ & $\begin{array}{l}\text { AC1. We have strong relationships with our extended eLearning in our enterprise. } \\
\text { AC2. We have a strong set of partnership with complementary eLearning players. }\end{array}$ & $\begin{array}{l}0.81 \\
0.85\end{array}$ & 0.82 & 0.69 \\
\hline \multirow[t]{2}{*}{$\begin{array}{l}\text { External } \\
\text { Opportunity-Recognizing } \\
\text { Integrative } \\
\text { Capabilities(EOR) }\end{array}$} & $\begin{array}{c}\text { EOR1. Observing customer's needs/problems because eLearning implementation. } \\
\text { EOR2.Observing product/service/process problems } \\
\text { because eLearning implementation. }\end{array}$ & 0.84 & 0.86 & 0.76 \\
\hline & eIN1. We are continually introducing new eLearning offer our employee. & 0.89 & \multirow{3}{*}{0.95} & \multirow{3}{*}{0.82} \\
\hline \multirow[t]{2}{*}{$\begin{array}{c}\text { eLearning } \\
\text { Innovation (eIN) }\end{array}$} & $\begin{array}{l}\text { eIN2. We have a strong, rapid development platform for eLearning applications. } \\
\text { eIN3. We have a strong, rapid development material for eLearning applications. }\end{array}$ & 0.94 & & \\
\hline & $\begin{array}{l}\text { eIN4. We continually innovation our eLearning functions } \\
\text { offerings through iterative projects adding to their functionality. }\end{array}$ & 0.87 & & \\
\hline
\end{tabular}

Table 3. Test of hypotheses: individual relationships and mediated model analyses.

Table 3. Test of hypotheses: individual relationships and mediated model analyses.
\begin{tabular}{cc} 
Hypothesis Relationships & Standardized Lisrel Estimate \\
\hline H1 Alliance capability have a positive effect on eLearning Innovation. & $0.38^{* * *}$ \\
H2 External opportunity-recognizing integrative capabilities & $0.41^{* * *}$ \\
have a positive effect one Learning Innovation. & $0.68^{* * *}$ \\
H3 Alliance capability have a positive effect on external & \\
opportunity-recognizing integrative capabilities. & $0.28^{* * *}$ \\
H4 External Opportunity-Recognizing Integrative &
\end{tabular}
Capabilities mediate the positive effect of Alliance capability on eLearning Innovation.

The path coefficient for $\mathrm{H} 3$ the resource stock of alliance capabilities had the strongest effect on external opportunity-recognizing integrative capabilities. Followed byH1 and $\mathrm{H} 2$ the alliance capabilities and external opportunity-recognizing integrative capabilities, it had a significant and positive effect on eLearning innovation. Integrative capability is an important mediating role, in alliance capabilities through integrative capabilities on eLearning innovation $(0.68 \times 0.41=0.28)$. In addition, we found that integrative capabilities are a mediator between alliance capabilities and eLearning innovation, which supports $\mathrm{H} 4$.

\section{Discussion and Conclusions}

We found that alliance capabilities and external opportunity-recognizing integrative capabilities had a positive direct effect on eLearning innovation. Alliance capabilities had a direct effect on eLearning Innovation, and through integrative capabilities on eLearning Innovation a value of 0.28 was gained, indicating a mediating relationship. The external opportunity-recognizing integrative capabilities lead to innovation primarily through the provision of a direction and opportunity context to deploy and utilize alliance capabilities, not merely by it sown 
direct effect. Within an organization, the adoption of new technology to increase competitive advantage has been hindered by an inherent lack of innovative awareness (Liao, Kickul, \& Ma, 2009). Analyzing the benefits, as in this study, no doubt, calls for the nurturing and utilization of alliance capabilities; integrative capabilities are very important capabilities on eLearning innovation. By exploring eLearning, an organization can leverage its information and experience and deftly apply new intelligence and knowledge within its framework and structure.

\section{References}

[1] Lin, M. (2014) An Exploration on the Relationship of Transformational Leadership, Innovation Atmosphere and E-Commerce Organization Innovation. Open Journal of Social Sciences, 2, 48-53. http://dx.doi.org/10.4236/jss.2014.29008

[2] Teece, D. (2007) Explicating Dynamic Capabilities: The Nature and Microfoundations of (Sustainable) Enterprise Performance. Strategic Management Journal, 28, 1319-1350. http://dx.doi.org/10.1002/smj.640

[3] Teece, D.J., Pisano, G. and Shuen, A. (1997) Dynamic Capabilities and Strategic Management. Strategic Management Journal, 18, 509-533. http://dx.doi.org/10.1002/(SICI)1097-0266(199708)18:7<509::AID-SMJ882>3.0.CO;2-Z

[4] Beckman, C.M. and Haunschild, P.R. (2002) Network Learning: The Effects of Partners' Heterogeneity of Experience on Corporate Acquisitions. Administrative Science Quarterly, 47, 92-124. http://dx.doi.org/10.2307/3094892

[5] Grant, R.M. and Baden-Fuller, C. (2004) A Knowledge Accessing Theory of Strategic Alliances. Journal of Management Studies, 41, 61-84. http://dx.doi.org/10.1111/j.1467-6486.2004.00421.x

[6] Elg, U. (2000) Firms’ Home Market Relationships: Their Role When Selecting International Alliance Partners. Journal of International Business Studies, 31, 169-177. http://www.jstor.org/stable/155627 http://dx.doi.org/10.1057/palgrave.jibs.8490895

[7] Lavie, D. and Rosenkopf, L. (2006) Balancing Exploration and Exploitation in Alliance Formation. Academy of Management Journal, 49, 797-818. http://dx.doi.org/10.5465/amj.2006.22083085

[8] Zhou, Q., Du, W. and Han, W. (2012) Technological Standard Alliance in China: Partner Selection and Innovation Performance. Journal of Science and Technology Policy in China, 3, 196-209. http://dx.doi.org/10.1108/17585521211268655

[9] Fey, C.F. and Beamish, P.W. (2001) Organizational Climate Similarity and Performance: International Joint Ventures in Russia. Organization Studies, 22, 853-882. http://dx.doi.org/10.1177/0170840601225005

[10] Heimeriks, K.H. and Duysters, G. (2007) Alliance Capability as a Mediator between Experience and Alliance Performance: An Empirical Investigation into the Alliance Capability Development Process. Journal of Management Studies, 44, 25-49. http://dx.doi.org/10.1111/j.1467-6486.2006.00639.x

[11] Park, S.H. and Ungson, G.R. (2001) Interfere Rivalry and Managerial Complexity: A Conceptual Framework of Alliance Failure. Organization Science, 12, 37-53. http://www.jstor.org/stable/2640395 http://dx.doi.org/10.1287/orsc.12.1.37.10118

[12] Rothaermel, F.T., Hitt, M.A. and Jobe, L.A. (2006) Balancing Vertical Integration and Strategic Outsourcing: Effects on Product Portfolio, Product Success, and Firm Performance. Strategic Management Journal, 27, 1033-1056. http://dx.doi.org/10.1002/smj.559

[13] Cohen, W.M. and Levinthal, D.A. (1990) Absorptive Capacity: A New Perspective on Learning and Innovation. Administrative Science Quarterly, 35, 128-152. http://dx.doi.org/10.2307/2393553

[14] Liao, J., Welsch, H., and Stoica, M. (2003)Organizational Absorptive Capacity and Responsiveness: An Empirical Investigation of Growth-Oriented SMEs. Entrepreneurship Theory andPractice,28(1), 63-85. http://dx.doi.org/10.1111/1540-8520.00032

[15] Zahra, S. and George, G. (2002) Absorptive Capacity: A Review, Reconceptualization and Extension. Academy of Management Review, 27, 185-203. http://www.jstor.org/stable/4134351

[16] Hartman, A., Sifonis, J. and Kador, J. (2000) Net Ready: Strategies for Success in the Economy. McGraw-Hill, New York.

[17] Liao, J.,Kickul, J.R. and Ma, H. (2009) Organizational Dynamic Capability and Innovation: An Empirical Examination of Internet Firms. Journal of Small Business Management, 47, 263-286. http://dx.doi.org/10.1111/j.1540-627X.2009.00271.x

[18] Hills, G.E., Lumpkin, G.T. and Singh, R.P. (1997) Opportunity Recognition: Perceptions and Behaviors of Entrepreneurs, in Frontiers of Entrepreneurship Research. Babson College, Wellesley, MA.

[19] Nunnally, J. (1978) Psychometric Theory. McGraw-Hill, New York. 